\title{
Correction of Error
}

Case 2: $D\left(c_{1}\right) \geq R>D\left(c_{3}\right)$, i.e., $c_{1} \leq F(R)<c_{3}$.

The optimal policy sequence is $F B E E^{s}$ where $E^{s}$ is the stationary state in the policy $E$, so that the competitive equilibrium path consists of three phases (see Figure 1). The movements of energy output and price during the first intereval $\left[0, T_{1}\right)$ are the same as those in Case 1. During the second interval $\left[T_{1}, T_{2}\right), x_{1 t}=D\left(p_{t}\right)>R, p_{t}=c_{1}+q_{10} \exp (r+k) t$ where $q_{10}>0$, and $x_{2 t}=x_{3 t}=0$. At $T_{2}$ the stock of the renewable resource is depleted, but the electric energy production using the constant rainfall, $R$,starts. During the third interval $\left[T_{2}, \infty\right), x_{1 t}$ $=D\left(p_{t}\right)=R$ where $p_{t}=F(R)$, and $x_{2 t}=x_{3 t}=0$. The backstop technology is not used forever.

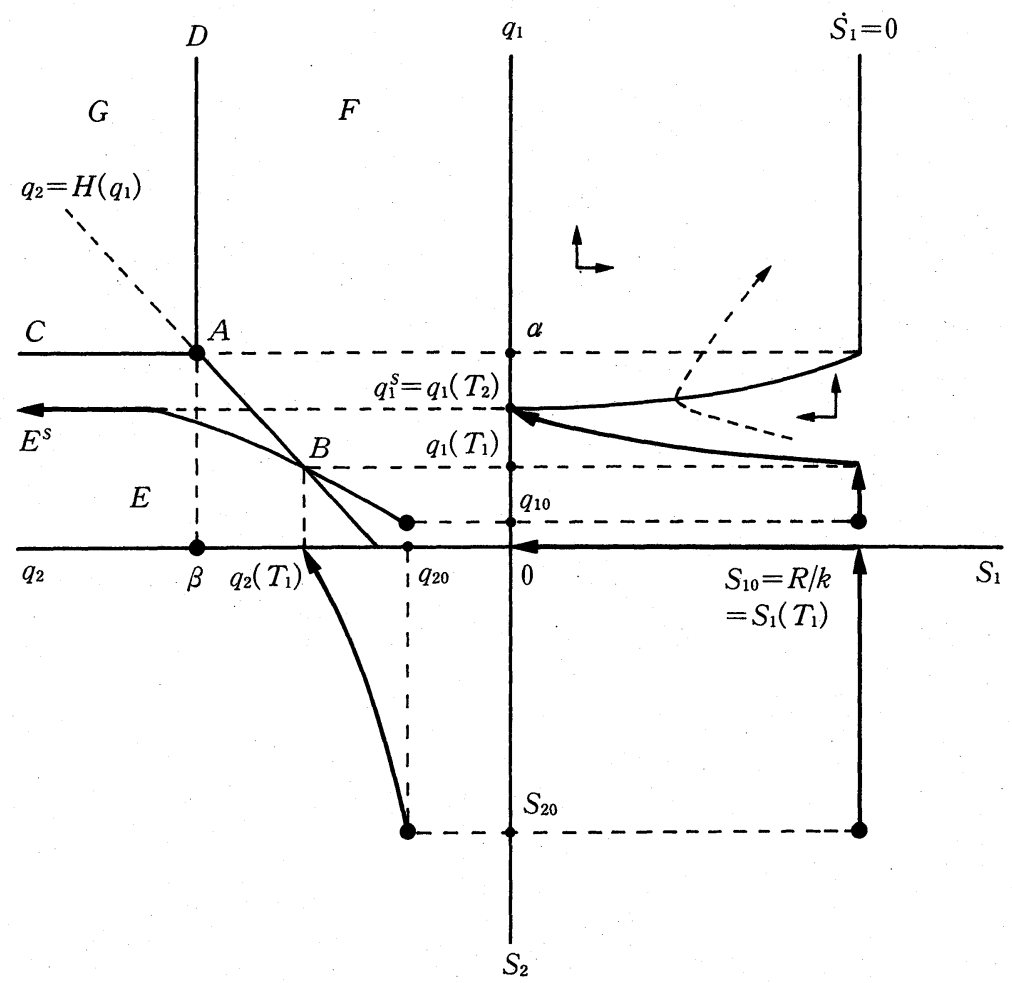

Figure 1. Optimal policy sequence $F B E E^{s}$

[Theorem 1, Case 2: $D\left(c_{1}\right) \geq R>D\left(c_{3}\right)$ ]

Case $3: D\left(c_{3}\right) \geq R$, i.e., $c_{3} \leq F(R)$.

This is the correction of page $\mathbf{5 2}$ of Yoshida (1991, "Economic Analysis of Electric Power Industry : Competition versus Monopoly", vol. 21 of this journal, 46-61). More specifically, Figure 1 is inserted between Case 2 and Case 3 as above.

The editor sincerely apologises that Figure 1 was not printed and begs readers to notice the corrected version. 